\title{
Gender Difference In Cognitive Style And Career Decision Making Difficulties Of College Students
}

\author{
Sidrah Shafeeq \\ \& \\ Mamoona Ismail Loona \\ Department of Psychology \\ International Islamic University Islamabad
}

\begin{abstract}
Career decision making difficulties are one of the pivotal concerns of the students as well as the educational counsellors. Decision making is effected by the cognitive styles. The present study aimed to investigate the gender difference in cognitive style and career decision making difficulties of college students. For this purpose, students $(\mathrm{N}=541)$ including both female $(\mathrm{N}=236)$ and male $(\mathrm{N}=305)$ from twelve different colleges of Rawalpindi and Islamabad were approached, and they filled the Cognitive Style Indicator (Cools \& Van den Broeck, 2007) and Career Decision-making Difficulties Questionnaire (Gati \& Saka, 2001). The results of present study revealed that male students scored significantly high as compared to female students on Planning, subscale of cognitive style. Moreover, female students scored significantly high as compared to male students on Readiness, sub-scale of career decision-making difficulties questionnaire and male students scored significantly high as compared to female students on Inconsistent information, sub-scale of career decision-making difficulties questionnaire. This indicates that female students have significantly less difficulties as compared to male students on inconsistent information, this finding is unique in Pakistani context, as previous researches conducted in Pakistan reports that male students have less career decision making difficulties as compared to female students.
\end{abstract}

Keywords: Cognitive Style, Career Decision-Making Difficulties, Gender Difference

\section{تلخيص}

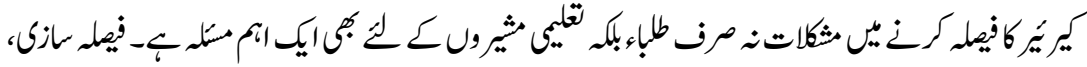

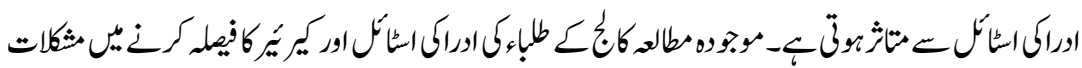

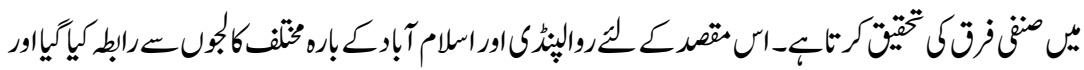

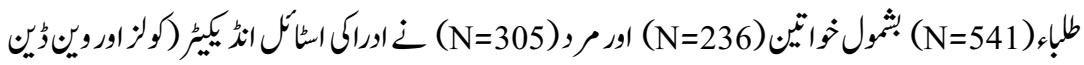

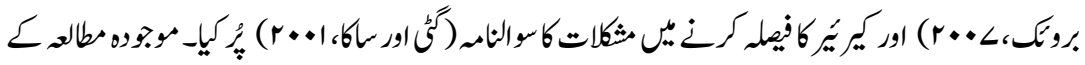

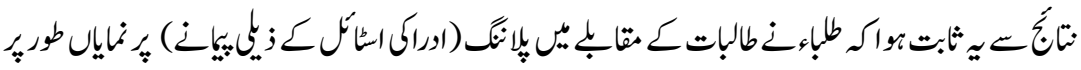

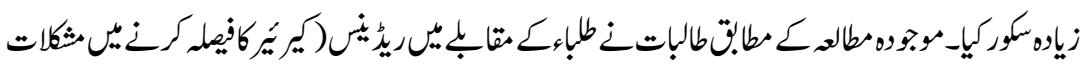




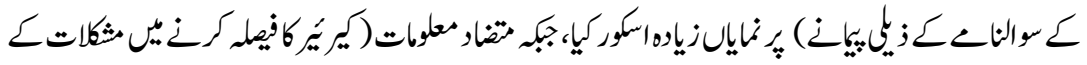

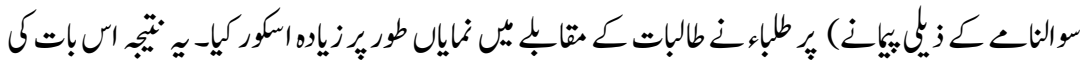

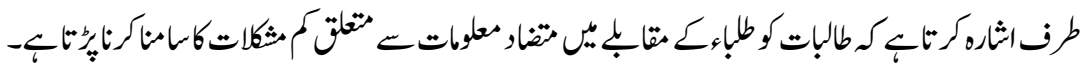

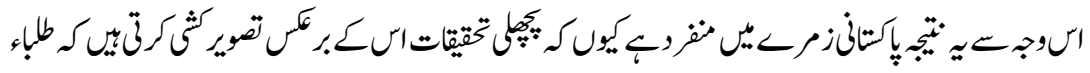

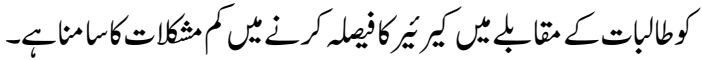

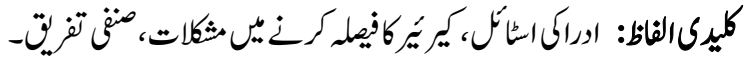

Career decision-making is one of the most important decisions for the personal and vocational satisfaction (Amir \& Gati, 2006). Some people make this careerdecision easily and others may have moderate difficulty, while still some others may face great difficulties associated with career decision making process (Gati et al., 1996). It was proposed by Gati (1990) and Gati et al. (1996) that career decision making difficulties may lead to helplessness, unhappiness and insecurity. If the students are unable to make their career decision adequately then they essentially suffer in term of low satisfaction with their career and life. So, there is a need to locate the difficulties of students related to career decision making process and provide them with sufficient help as a vocational counsellor.

As proposed by Feldman (2003) the cause of career decision making difficulties are the individual difference in cognitive style, vocational interest, personality, work experience, demographic status and family environment. Cognitive style has been researched with the career decision making. Results of the study conducted by Creed, et al. (2004) suggest that people with less optimistic cognitive style are more prone to have career indecision. In fact, cognitive style particularly optimism is considered as an important factor in career decision making and career development in adolescent at high school and university.

Moreover, Creed, et al. (2002) explored the optimistic and pessimistic cognitive style with the career decision-making, career maturity and career goal in high school students and found that optimistic cognitive style is related to career maturity more career goals and high satisfaction with the career decision making and pessimistic cognitive style is more related to less career goals and problems related to career decision-making. Alexander, et al. (2014) found that optimistic cognitive style correlated significantly with career certainty, i.e. if people show optimistic cognitive style then they can be more certain about their career as compared to people with less optimistic cognitive style. Lazarus (1991); Luzzo and Jenkins-Smith (1998); Powell and Luzzo (1998); found that optimistic cognitive style is more related to career maturity, career decision-making and career development. 
The taxonomy of career decision making difficulties is based on decision making theory (Gati, et al., 2011). It postulates that any deviation of behaviour from the decision making behaviour of an ideal career decision maker will lead to the difficulty in the process of career decision-making. Career decision-making difficulties have major three categories i.e., lack of readiness, lack of information and inconsistent information. These three major categories are further sub-divided in the ten sub-categories i.e., lack of motivation, general indecisiveness, dysfunctional beliefs, career decision-making process, lack of information about self, lack of information about occupation, ways of obtaining data, unreliable information, internal conflicts and external conflicts (as shown in figure 1).

Career decision-making difficulties are the growing concerns of the college students as compared to other students at higher level, because they are on the verge of deciding about their university major subject and career consequently. University students have less career decision making difficulties as compared to students in the last year of high school and interns with on the job training (Di Fabio et al., 2015; Gati \& Saka, 2001). High scores on career decision making difficulties are related to the low self-esteem and low environmntal mastery (Ali \& Shah, 2013).

Various studies includes research on career decision making difficulties from the perspective of exploring gender difference, results of some of these studies are conferred in the following lines. Perceptions of career barriers have gender differences as identified by Swanson and Toker (1991a, 1991 b), in EuroAmerican College Students. They found that males perceive financial issues as career barrier and females percieve that they have to sacrifies their career for their family. McWhirter (1997) also reported that Maxican-American and EuroAmerican female high school students percieve more career barriers as compared to male high school students. Albion (2000) conducted a research on career decision making difficulties of adolescent boys and girls. He found that there is no gender difference in the overall level of career decision making difficulties, moreover he found that boys had more information about career and girls were more interested in career yet show more flexible behavior regarding career. Turkish high school adolesent boys reported greater difficulties regarding lack of motivation and adolescent girls reported more difficulties in general indecisiveness and dysfunctional belief (Bacanli, 2008). 


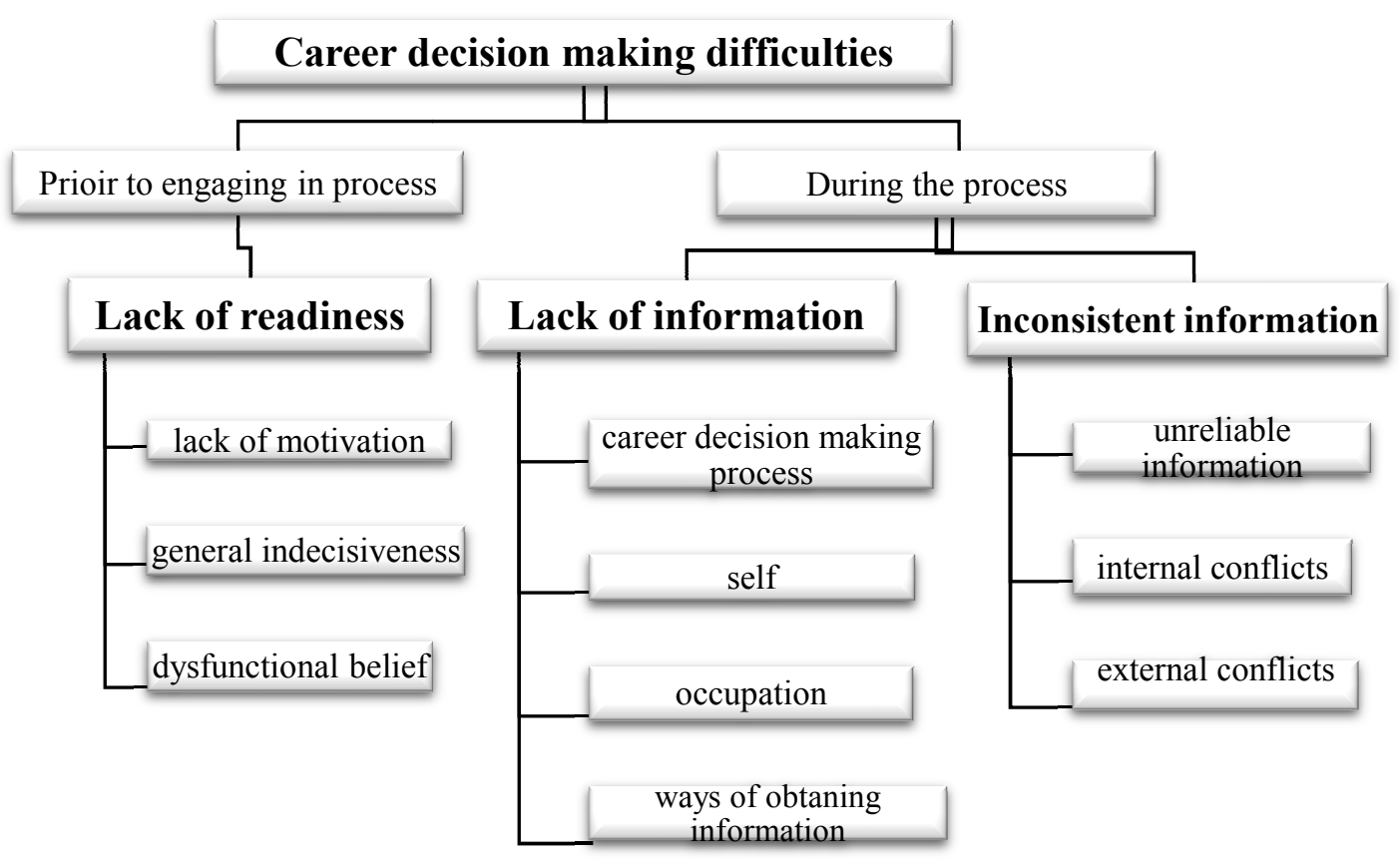

Figure 1: Taxonomy of Career Decision Making Difficulties

Studies focused on gender difference in career decision making difficulties in the context of Pakistan have reported that overall female students percieve greater difficulties as compare to male students. Results of few such researches are discoursed in the following paragraph.

Inam and Gillani (2006) reported that male face less difficulty as compared to female on inconsistent information, a sub-scale of CDDQ. Moreover there is non significant gender difference observed on the career decision-making difficulties questionnaire. Kiran and Anwar (2006) found that girls score more on career decision making difficulties questionaire as compared to boys. She also reported that the girls score higher on the sub-scales of career decision-making difficulties questionnaire but the difference is significant for lack of readiness only and is non-significant for he other two sbb-scales of CDDQ, i.e., lack of information and inconsistent information.

Hayes and Allinson (1994), have reported that cognitive style is related to learning, perception, problem solving and decision-making. Cools and Van den Broeck, (2007) have defined cognitive style is the way people perceive stimuli, gather information and apply this knowledge to solve a problem. Rayner and Cools (2011) demarcated cognitive styles as the steady individual variance in perceiving, organizing and processing information. 
Cools and Van den Broeck (2007) have identified a three dimentional model for cognitive style, a cognitive style indicator (CoSI). CoSI consists of three individual unipolar cognitive styles, i.e. knowing style, planning style and creating style (as shown in figure 2). People with knowing style are more concerned for fact and data. They try to memorize facts and figure; and can solve the problem in a logical manner. People with planning style have more affinity for structred and well organized things. They prefer a work enviroment which is more structed and has proper instruction. People with creating style are more flexible and enjoys freedom of applying innovative solutions for problems, they prefer experimentation.

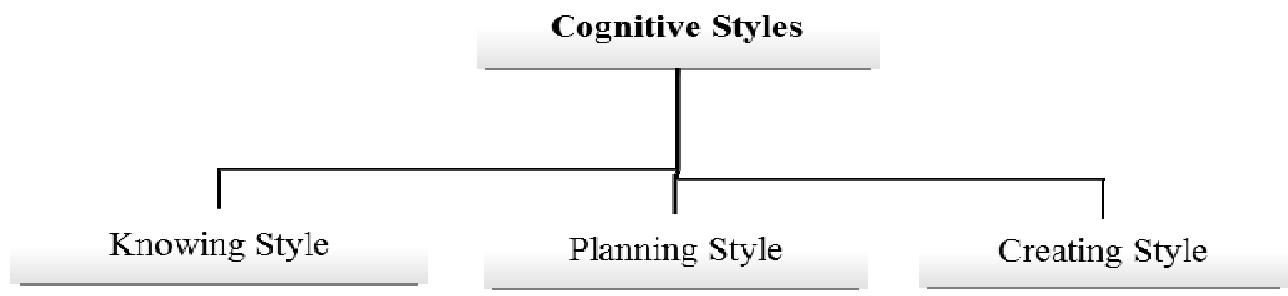

Figure 2: Taxonomy of Cognitive Styles

Most of the researches have found non-significant gender difference on cognitive styles but Riding and Agrell (1997), have found that males are more analytical as compared to females regarding their cognitive style. Petrone (2000) reported that males have more developed vocational identity as compared to females and have more optimistic approach regarding the future success of their career. Optimistic cognitive style is more positively and significantly related to career certanity among university students (Alexander, et al., 2014).

Previous research support this notion that gender difference is prevalent in career decision making difficulties of students at various levels, therefore the aim of the present research is explore the gender difference in career decision-making difficulties of college students. Cognitive style is influential in decision making, it was corelated with various career related variable i.e., internal and external career barriers, career choice etc (Creed, et al., 2004; Alexander, et al., 2014), but gender differnce was not observed specifically. So the present study will explore the gender difference in cognitive styles of college students. The goal of the present study is to locate the career decision-making difficulties of the college students and to locate the gender difference in career decision making difficulties of the college students. Moreover, the present study will also explore the gender difference in cognitive styles of students, as cognitive style is related to career decision-making (Hayes \& Allinson, 1994).

The objective of this study was to assess the gender difference in cognitive styles and career decision making difficulties of college students, moreover, following hypotheses were formulated for the present study: 
- Female students will score high on career decision making difficulties i.e., lack of readiness, lack of information and inconsistent information, as compared to male students.

- There will be significant gender difference among the three domains of cognitive styles indicator i.e. knowing, planning and creating style.

\section{Research Method}

The sample size of the present study was 541 college students of Rawalpindi $(\mathrm{n}=315)$ and Islamabad $(\mathrm{n}=226)$, including both girls $(\mathrm{n}=236)$ and boys $(\mathrm{n}=305)$ of 1st Year $(\mathrm{n}=359)$ and $2 \mathrm{nd}$ Year $(\mathrm{n}=182)$. The age range of the students was 14-25 years $(\mathrm{M}=17.03, \mathrm{SD} .=1.06)$ (See Table 1). 563 college students were handed over the questionnaires of the present study based on purposive sampling technique, only 541 had returned the filled questionnaires, 22 students had given incomplete information either demographic information or information on the given scales. The incomplete questionnaires were excluded from the collected data and were not considered for statistical analysis.

\section{Instruments}

Following instruments were used in the study.

\section{Cognitive Style Indicator (CoSI)}

It was developed by Cools and Van den Broeck (2007). It is a five-point Likert scale ranging from 1- totally disagree to 5- totally agree. It comprise of 18-item. Item and factor analyses confirm the three-dimensional cognitive style model, with Cronbach alpha co-efficient in this study were $0.78,0.83$, and 0.77 for the knowing, planning, and creating style respectively.

\section{Career Decision Making Difficulties Questionnaire (CDDQ)}

The abridged, 34-item version of the CDDQ developed by Gati and Saka (2001) was used. It is a 9-point Likert scale ranging between 1-does not describe me and 9-describes me well. Each item of CDDQ describes a decision-making situation and the participants must rate it. Three major dimensions of the CDDQ are lack of readiness, lack of information and inconsistent information, which are further divide in ten categories. Gati et al. (1996) reported internal consistency reliability coefficients of .71, .91, and .93 for the three major clusters.

\section{Procedure}

Researcher herself approached the principals and concerned personals of twentythree colleges of Rawalpindi and Islamabad, out of which twelve colleges approved the data collection from their respective students. Researcher gathered information from the respective class of the students and gave them instructions 
verbally to the respective class of students and handed them the questionnaires. Students filled the questionnaires and returned to the researcher in forty-five minutes. Five colleges didn't give the permission to the researcher to interact with the students; therefore the researcher handed over the questionnaire to the concerned personnel and explains him/her the procedure. The researcher collected the filled questionnaire from the same personnel on the next day by hand.

\section{Results}

Table: 1

Frequencies and percentages of demographic variables

\begin{tabular}{|c|c|c|c|c|c|c|}
\hline & \multicolumn{2}{|c|}{$\begin{array}{c}\text { Male } \\
n=305\end{array}$} & \multicolumn{2}{|c|}{$\begin{array}{c}\text { Female } \\
N=236\end{array}$} & \multirow[b]{2}{*}{ Mean } & \multirow[b]{2}{*}{ SD } \\
\hline & $f$ & $\%$ & $\mathrm{f}$ & $\%$ & & \\
\hline Age & & $56.4 \%$ & & $43.6 \%$ & 17.03 & 1.16 \\
\hline \multicolumn{7}{|l|}{ Class } \\
\hline $1^{\text {st }}$ year & 226 & $63.0 \%$ & 133 & $37.0 \%$ & & \\
\hline $2^{\text {nd }}$ year & 79 & $43.4 \%$ & 103 & $56.6 \%$ & & \\
\hline \multicolumn{7}{|l|}{ City } \\
\hline Rawalpindi & 207 & $65.7 \%$ & 108 & $34.3 \%$ & & \\
\hline Islamabad & 98 & $43.4 \%$ & 128 & $56.6 \%$ & & \\
\hline
\end{tabular}

The sample consisted of 541 college students including girls $(\mathrm{n}=236)$ and boys $(n=305)$. The age range of the students was $14-25$ years $(M=17.03$, SD. $=1.06)$.

Table: 2

Gender Difference in Cognitive Style Indicator (CoSI) and Its Sub-scales

\begin{tabular}{|c|c|c|c|c|c|c|c|c|c|}
\hline \multirow[t]{2}{*}{ Sub-scales } & \multicolumn{2}{|c|}{$\begin{array}{c}\text { Male } \\
(n=305)\end{array}$} & \multicolumn{2}{|c|}{$\begin{array}{l}\text { Female } \\
(n=236)\end{array}$} & \multirow[t]{2}{*}{$\begin{array}{c}\mathbf{t} \\
(539)\end{array}$} & \multirow[t]{2}{*}{$\mathbf{p}$} & \multicolumn{2}{|c|}{$95 \% \mathrm{CI}$} & \multirow[t]{2}{*}{$\begin{array}{c}\text { Cohen's } \\
\text { d }\end{array}$} \\
\hline & $\mathbf{M}$ & SD & M & SD & & & $\mathbf{L L}$ & $\mathbf{U L}$ & \\
\hline Knowing & 8.90 & 2.75 & 8.47 & 2.70 & 1.79 & .07 & -0.04 & 0.89 & 0.16 \\
\hline Planning & 15.35 & 4.39 & 14.34 & 3.92 & 2.77 & .00 & 0.29 & 1.72 & 0.24 \\
\hline Creating & 16.01 & 4.13 & 15.92 & 4.09 & .25 & .79 & -0.61 & 0.79 & 0.02 \\
\hline Total CoSI & 40.25 & 9.53 & 38.72 & 8.70 & 1.92 & .05 & -0.04 & 3.08 & 0.17 \\
\hline
\end{tabular}

Note: $\mathrm{CI}=$ Class Interval; $\mathrm{LL}=$ Lower Limit; $\mathrm{UL}=$ Upper Limit $\mathrm{p}<.05, \mathrm{p}<.01$

Table 2 indicated that there was a significant difference in the score of planning and total COSI between male $(\mathrm{M}=15.35, \mathrm{SD}=4.39)$ and female $(\mathrm{M}=14.34$, $\mathrm{SD}=3.92$ ). These results suggested that male were better on planning as compared to females. 
Table: 3

Gender difference in career decision-making difficulties questionnaire (CDDQ) and Its sub-scales

\begin{tabular}{|c|c|c|c|c|c|c|c|c|c|}
\hline \multirow[t]{2}{*}{ Sub-scales } & \multicolumn{2}{|c|}{$\begin{array}{c}\text { Male } \\
(\mathrm{n}=\mathbf{3 0 5})\end{array}$} & \multicolumn{2}{|c|}{$\begin{array}{l}\text { Female } \\
(n=236)\end{array}$} & \multirow[t]{2}{*}{$t(539)$} & \multirow[t]{2}{*}{$p$} & \multicolumn{2}{|c|}{$95 \%$ CI } & \multirow[t]{2}{*}{$\begin{array}{c}\text { Cohen's } \\
\text { d }\end{array}$} \\
\hline & $\mathbf{M}$ & SD & M & SD & & & $\mathbf{L L}$ & UL & \\
\hline Readiness & 55.72 & 12.94 & 58.15 & 14.03 & $\begin{array}{l}-2.09 \\
\end{array}$ & .03 & -4.72 & -0.15 & 0.18 \\
\hline Lack of Info & 59.24 & 22.17 & 55.54 & 25.63 & 1.80 & .07 & -0.34 & 7.75 & 0.15 \\
\hline $\begin{array}{l}\text { Inconsistent } \\
\text { information }\end{array}$ & 47.67 & 17.64 & 41.51 & 18.62 & 3.93 & .00 & 3.09 & 9.24 & 0.34 \\
\hline Total CDDQ & 162.63 & 44.51 & 155.20 & 48.99 & 1.84 & .06 & -0.49 & 15.35 & 0.16 \\
\hline
\end{tabular}

Note: $\mathrm{CI}=$ Class Interval; $\mathrm{LL}=$ Lower Limit; $\mathrm{UL}=$ Upper Limit $\mathrm{p}<.05, \mathrm{p}<.01$

Table 3 indicated significant difference on Readiness between males $(M=55.72$, $\mathrm{SD}=12.94)$ and females $(\mathrm{M}=58.15, \mathrm{SD}=14.03)$. Females had high mean score on readiness as compared to male. Table 3 also indicated significant difference in the mean scores on inconsistent information subscale of CDDQ. Males had high scores on inconsistent information as compared to females.

\section{Discussion}

The present study aimed at finding the gender difference in career decisionmaking difficulties of college students. It was hypothesized that female students will have high score on career decision-making difficulties as compared to male students. The hypothesis was partially accepted as female students have significantly low mean score on readiness, a sub-scale of CDDQ, as compared to male students, and female students have significantly high mean score on inconsistent information, a sub-scale of CDDQ, as compared to male students.

This indicates that female students have less career decision making difficulties on readiness. The results are like research findings of Bacanli (2008), which indicate that boys have lack of motivation, a sub-category of lack of readiness. May be now a day's girls are showing more concern for the career and motivated therefore they take more time in thinking about the relevant career choice as compared to male students. Moreover, this result was inconsistent with the research findings of Kiran and Anwar (2006), which shows that girls will have higher score on career decision making difficulties and its subscale; moreover, Inam and Gillani (2006) showed that female students have significantly high score on inconsistent information as compared to male students.

Female students have significantly low score and difficulty on inconsistent information as compared to male students, which indicates that male students have significantly higher difficulties on inconsistent information as compare to female students. This result is in contradiction with the previous research by 
Kiran and Anwar (2006), Inam and Gillani (2006), Bacanli (2008), Gati and Saka (2001), as the research finding of the above studies indicate that girls will experience more difficulties on inconsistent information as compared to boys.

The t-test score of cognitive style indicator reveal that male students show significantly high score on planning style as compared to female students. This indicates that male students want more structured and detailed plan regarding decision making in general. The results are in congruence with the western culture where, Riding and Agrell (1997) have found that males are more analytical as compared to females regarding their cognitive style.

Implications of the present study are for the students, educational counsellors, education institutes in general. By finding the gender difference the educational institutes can modify their selection procedure of the students in colleges and universities. Moreover, educational counsellors can guide the students regarding career decision making accordingly.

Although the sample size of the present study is adequate but there can be some limitations i.e.

- For the present research sample was selected from the two cities of Pakistan, in the future research sample can be taken from more than two cities or even from other provinces to make the results more generalize.

- Furthermore, in the present study only college students were selected as the sample, in future research students from school and universities can also be taken as the sample.

\section{Conclusions}

Career decision making difficulties are the major issues to be addressed by the educational counsellors as the students are unable to decide about their career and need guidance. Additionally, cognitive style influences the decision-making process so it is also related to career decision making difficulties of students. The present study explored the gender difference of the career decision making difficulties and cognitive style. Finding of the current study revealed that female students have significantly higher difficulties on readiness and significantly less difficulties on inconsistent information as compared to male students. Besides that, male students have significantly higher score on planning style which indicates that male students have more structured cognitive style as compared to female students. The findings of the present study are beneficial for the students, career counsellors and educational institutes. 


\section{Recommendations}

- Career guidance/counseling should be provided to the students at high school or college level.

- Career guidance/counseling strategies should be modified for male and female students respectively, as they encounter different difficulties in career decision-making process.

- Longitudinal studies can be conducted to find the impact of career guidance/counseling on the career success and satisfaction of the students.

- Qualitative data regarding career decision-making should be collected along with the quantitative data for further explanation of the phenomenon of decision-making in educational settings.

\section{References}

Albion, Majella J. (2000). Career Decision Making Difficulties of Adolescent Boys and Girls. Australian Journal of Career Development, vol.9:2, pp.14-19.

Alexander, V. E., Bartrum, D. A. \& Hicks, R. E. (2014). Emotional Intelligence and Optimistic Cognitive Style in Certainty in Career Decision Making. GSTF Journal of Psychology, vol.1:2.

Ali, U. \& Shah, E. (2013). Career Decision Difficulty as a Predictor of Environmental Mastery and Self Esteem in College Students. ProcediaSocial and Behavioral Sciences, vol.84, pp.1119-1123.

Amir, T., \& Gati, I. (2006). Facets of Career Decision-Making Difficulties. British Journal of Guidance \& Counselling, vol.34:4, pp.483-503.

Bacanli, F. (2016). Career Decision-Making Difficulties of Turkish Adolescents. International Journal for Educational and Vocational Guidance, vol.2:16, pp.233-250.

Cools, E., \& Van den Broeck, H. (2007). Development and Validation of the Cognitive Style Indicator. The Journal of Psychology, vol.141:4, pp.359-387.

Creed, P. A., Patton, W. \& Bartrum, D. (2002). Multidimensional Properties of the LOT-R: Effects of Optimism and Pessimism on Career and Wellbeing Related Variables in Adolescents. Journal of Career Assessment, vol.10, pp.42-61. 
Creed, P. A., Patton, W., \& Bartrum, D. (2004). Internal and External Barriers, Cognitive Style, and the Career Development Variables of Focus and Indecision. Journal of Career Development, vol.30:4, pp.277-294.

Di Fabio, A., Palazzeschi, L., Levin, N. \& Gati, I. (2015). The Role of Personality in the Career Decision-Making Difficulties of Italian Young Adults. Journal of Career Assessment, vol.23, pp.281-293.

Feldman, D. C. (2003). The Antecedents and Consequences of Early Career Indecision among Young Adults. Human Resource Management Review, vol.13:3, pp.499-531.

Gati, I. (1990). Why, When, and How to Take into Account the Uncertainty Involved in Career Decisions. Journal of Counselling Psychology, vol.37, pp.277-280.

Gati, I., Krausz, M. \& Osipow, S. H. (1996). A Taxonomy of Difficulties in Career Decision Making. Journal of Counseling Psychology, vol.43, pp.510-526.

Gati, I. \& Saka, N. (2001). High School Students' Career-Related DecisionMaking Difficulties. Journal of Counseling and Development: JCD, vol.79:3, p.331.

Gati, I., Krausz, M. \& Osipow, S.H. (2011). Abridged Professional Manual for the Career Decision-making Difficulties Questionnaire $(C D D Q)$

Hayes, J. \& Allinson, C. W. (1994). Cognitive Style and its Relevance for Management Practice. British Journal of Management, vol.5, pp.53-71.

Inam, A. \& Gillani, N. (2006). Identity Status, Psychological Wellbeing and Career Decision Making Difficulties among Educated Adults. Unpublished Manuscript. National Institute of Psychology, Quaid-i-Azam University, Islamabad, Pakistan

Kiran, A. \& Anwar, M. (2006). Career Decision Making Difficulties among Students. Unpublished Manuscript. National Institute of Psychology, Quaid-i-Azam University, Islamabad, Pakistan

Lazarus, R. (1991). Emotions and Adaptation. Plenum Press: New York.

Luzzo, D. A. \& Jenkins-Smith, A. (1998). Development and Initial Validation of the Assessment of Attributions for Career Decision-Making. Journal of Vocational Behavior, vol.52:2, pp.224-245. 
McWhirter, E. H. (1997). Perceived Barriers to Education and Career: Ethnic and Gender Differences. Journal of Vocational Behavior, vol.50:1, pp.124-140.

Petrone, M. M. (2000). Measuring Competence for Career Decision Making. (Doctoral Dissertation). Dissertation Abstracts International: Section B: The Sciences and Engineering, 61(6-B): 3308.

Powell, D. F. \& Luzzo, D. A. (1998). Evaluating Factors Associated with the Career Maturity of High School Students. The Career Development, vol.47, pp.145-158.

Rayner, S.J. \& Cools, E. (Eds.) (2011). Style Differences in Cognition, Learning, and Management: Theory, Research and Practice. New York: Routledge, New York. Retrieved from: https://books.google.com.pk/books?hl=en\&lr= \&id=JU1P8KNWq8UC\&oi=fnd\&pg=PP2\&dq=Rayner, + S.J., $+\% 26+$ Cools ,+ E. $+($ Eds. $)+(2010) .+$ Style+Differences + in + Cognition, + Learning,,+ and + Management:+Theory,+Research+and+Practice.+New+York:+Routledge, + in + press.\&ots $=$ OcN_vKJ0ie\&sig=puXoqR8YtsnCL-pHtHN7sFLdG1 A\# $\mathrm{v}=$ onepage $\& \mathrm{q} \& \mathrm{f}=\mathrm{false}$

Riding, R., \& Agrell, T. (1997). The Effect of Cognitive Style and Cognitive Skills on School Subject Performance. Educational Studies, vol.23:2, pp.311-323.

Swanson, J. L. \& Tokar, D. M. (1991a). College Students' Perceptions of Barriers to Career Development. Journal of Vocational Behavior, vol.38, pp.92-106.

Swanson, J. L., \& Tokar, D. M. (1991b). Development and Initial Validation of the Career Barriers Inventory. Journal of Vocational Behavior, vol.39, pp.344-361.

Sidrah Shafeeq is MS Scholar in the Department of Psychology, International Islamic University Islamabad.

Dr. Mamoona Ismail Loona is an Assistant Professor in the Department of Department of Psychology (Women Campus), International Islamic University Islamabad. 